\title{
In vitro fermentation of selected xylo-oligosaccharides by piglet intestinal microbiota
}

\author{
Patrícia Moura ${ }^{\text {a,b }}$, Susana Cabanas ${ }^{\text {a }}$, Paula Lourenço ${ }^{\text {a }}$, Francisco Gírio ${ }^{\text {a }}$, \\ Maria C. Loureiro-Dias ${ }^{c}$, M. Paula Esteves ${ }^{a}$,* \\ ${ }^{a}$ Instituto Nacional de Engenharia, Tecnologia e Inovação, Departamento de Biotecnologia, Estrada do Paço do Lumiar, 22, 1649-038 Lisboa, Portugal \\ ${ }^{\mathrm{b}}$ Egas Moniz, Cooperativa de Ensino Superior, Quinta da Granja, 2829-511 Caparica, Portugal \\ ${ }^{\mathrm{c}}$ Instituto Superior de Agronomia, Universidade Técnica de Lisboa, 1349-017 Lisboa, Portugal
}

Received 23 May 2007; received in revised form 22 October 2007; accepted 13 November 2007

\begin{abstract}
The objective of this study was to compare the in vitro fermentability of xylo-oligosaccharides (XOS) with different degrees of polymerisation (DP) by the intestinal digesta collected in three distinct intestinal sections of the porcine intestinal tract: ileum, caecum, and distal colon. The studied oligosaccharides included commercial short-chain XOS (DP 2-5), and medium-chain (DP 2-14) and long-chain (DP 2-25) XOS obtained by autohydrolysis of brewery's spent grain (BSG), corn cobs (CC) and Eucalyptus globulus wood (EUC). The oligosaccharide and monosaccharide consumption, lactate and short-chain fatty acids concentrations were correlated with shifts on PCR titres of Bacteroides/ Prevotella, Bifidobacterium and Lactobacillus/Pediococcus populations, by using group- and genus-specific primers.

All tested XOS were extensively fermented by the piglet ileal, caecal and colonic microbiota. The rate of consumption of medium- and longchain XOS was notably reduced in the fermentations by the ileal inoculum as compared to commercial XOS. EUC XOS, CC XOS and commercial XOS supported an enhancement of bifidobacteria and lactobacilli replication in a first stage of the fermentations. Apparently this stimulation was not selective, because Bacteroides/Prevotella replication increased in a second stage of the fermentations, coincident in time with the highest consumption rates of some XOS mixtures tested. Mostly due to the slow fermentability by the ileal microbiota, medium-chain and long-chain XOS mixtures can be regarded as promising functional candidates suitable to act as distally fermentable substrates.
\end{abstract}

(C) 2007 Swiss Society of Food Science and Technology. Published by Elsevier Ltd. All rights reserved.

Keywords: Xylo-oligosaccharides; Piglet intestinal microbiota; Autohydrolysis; Degree of polymerisation; Prebiotic

\section{Introduction}

The prebiotic properties of some non-digestible oligosaccharides (NDO) and polysaccharides, namely fructo-oligosaccharides (FOS), transgalacto-oligosaccharides (TGOS) and inulin, have been extensively studied and there is great evidence of the physiological effects and health consequences of their consumption (Gibson, McCartney, \& Rastall, 2005; Pool-Zobel, 2005; Watzl, Girrbach, \& Roller, 2006). Other oligosaccharides (OS), such as xylo-oligosaccharides (XOS), isomaltooligosaccharides (IMOS) and soy-oligosaccharides (SOS) are

\footnotetext{
* Corresponding author. Tel.: +351 210924600; fax: +351 217163636.

E-mail address: paula.esteves@ineti.pt (M.P. Esteves).
}

classified as "emerging prebiotics", presenting a promising prebiotic potential although they still lack of strong scientific evidence (Gibson, Probert, Van Loo, Rastall, \& Roberfroid, 2004; Tuohy, Rouzaud, Bruck, \& Gibson, 2005).

Okazaki, Fujikawa, and Matsumoto (1990) were pioneers in the study of the prebiotic effects of XOS. These authors observed a significant but transient increase in bifidobacterial numbers and organic acids levels in the faeces of human volunteers consuming short-chain XOS. Similar bifidogenic effects were described in rats and mice consuming XOS, more notably in animals presenting lower initial bifidobacterial numbers (Campbell, Fahey, \& Wolf, 1997; Morishita, Yamada, Shiiba, Kimura, \& Taniguchi, 1993). XOS-dependent bifidobacterial up-shifts observed in vivo are consistently supported 
by in vitro studies (Crittenden et al., 2002; Jaskari et al., 1998; Moura, Barata, et al., 2007; Palframan, Gibson, \& Rastall, 2003). However, the evidence for a selective stimulation of bifidobacterial growth by XOS has not been demonstrated. Microorganisms belonging to Bacteroides, Clostridium and Lactobacillus genera are also able to metabolise XOS mixtures mainly composed by xylobiose and xylotriose (Crittenden et al., 2002; Van Laere, Hartemink, Bosveld, Schols, \& Voragen, 2000). However, more complex XOS structures have presented a higher capability to be selectivity fermented by bifidobacteria (Van Laere et al., 2000).

XOS can be produced by autohydrolysis of xylan-rich materials, such as byproducts from agricultural, agro-industrial and forestry origin (Garrote, Domínguez, \& Parajó, 1999a; Garrote, Domínguez, \& Parajó, 1999b). The process promotes hydrolysis of the hemicellulosic fraction of lignocellulosic materials and, although it consists of a non-selective fractionation process, the operational conditions can be optimised for XOS production. Chemically, XOS produced by autohydrolysis are constituted by a $\beta$ - $(1 \rightarrow 4)$-D-xylopyranose backbone which can be more or less substituted, depending on the feedstock material and the severity of the hydrothermal treatment (Carvalheiro, Garrote, Parajó, Pereira, \& Gírio et al., 2005; Ebringerová, Hromádková, \& Heinze, 2005). The crude XOS hydrolysates can be separated by gel filtration chromatography (GFC), and selected fractions can be pooled to obtain a desired average molecular weight range. This possibility enables the preparation of XOS mixtures with increased molecular weight, theoretically more capable to persist throughout the gastrointestinal (GI) tract and to support a saccharolytic fermentation up to more distal compartments of the intestinal tract when compared to short-chain XOS (Rastall \& Maitin, 2002; van de Wiele, Boon, Possemiers, Jacobs, \& Verstraete, 2007).

As NDO with promising prebiotic potential, XOS produced by autohydrolysis may constitute a dietary alternative to antimicrobial growth promoters, whose inclusion in animal diets has recently been banned in Europe (Patterson, 2005). In this study, we conducted a comparative study on the fermentability of commercial short-chain XOS and longer-chain XOS obtained by autohydrolysis. Our aim was to identify differences which could be of relevance concerning XOS prebiotic potential and its use as feed supplements.

\section{Material and methods}

\subsection{Feedstock materials and preparation of purified XOS series}

Chips of E. globulus wood (EUC) were obtained from ENCE Complejo Industrial de Pontevedra, Puentemolinos, Lourizan (Spain). Corn cobs (CC) and brewery's spent grain (BSG) were supplied by Casa Agrícola Monte Real, Salvaterra de Magos (Portugal) and Sociedade Central de Cervejas, Vialonga (Portugal), respectively. Crude XOS-rich hydrolysates of CC, obtained as previously described (Garrote et al., 1999b) were received from J.C. Parajó (University of Vigo,
Ourense, Spain). Crude de-starched XOS-rich hydrolysates of BSG were obtained from F. Carvalheiro (Carvalheiro, Esteves, Parajó, Pereira, \& Gírio, 2004). Gram-quantities of purified XOS series (DP 2-25) from EUC crude hydrolysates, prepared as described by Kabel, Schols, and Voragen (2002), were received from $\mathrm{H}$. Schols (Wageningen University, Wageningen, the Netherlands).

CC and BSG XOS-rich hydrolysates were purified and characterized as described by Moura, Barata, et al. (2007). Briefly, the liquid phases obtained from the autohydrolysis treatments were pooled together for separation of xylo-oligosaccharides (XOS) in a preparative gel filtration chromatography (GFC) column BPG 100/950 (Amersham Pharmacia Biotech, Uppsala, Sweden) filled with Superdex $30^{\mathrm{TM}}$. The system was equipped with a refractive index detector (K-2401 Knauer, Berlin, Germany). Separated fractions were collected into plastic bottles using a Super-frac ${ }^{\mathrm{TM}}$ collector (Amersham Pharmacia Biotech) and characterised in terms of apparent molar mass in a LaChrom HPLC system (Merck, Darmstadt, Germany) equipped with three in-series size exclusion chromatography columns BIOSEP-SEC (Phenomenex, Torrance, USA), S4000, $\mathrm{S} 3000$ and $\mathrm{S} 2000$, using $50 \mathrm{mM} \mathrm{NaNO}$ as eluent at $30{ }^{\circ} \mathrm{C}$, and a RI detector (Merck L-7490). Calibration was performed with external standards of xylose, maltose, maltotriose, stachyose and dextrans (Sigma, St. Louis, USA) with molecular weights ranging from 1000 to $580,000 \mathrm{Da}$. Calibration was used to delimit the ranges of the GFC fractions of CC XOS and BSG XOS to be pooled together. The BSG XOS and CC XOS pools had an estimated apparent molar mass ranging from 1760 to $429 \mathrm{Da}$ and 2160 to $286 \mathrm{Da}$, respectively, that correspond to average degrees of polymerisation (DP) from 12 to 3 , and 14 to 2, respectively. The pools were freeze-dried (Labconco, Kansas City, USA) prior to the use in the fermentation assays. The Kjeldahl method was used to determine the nitrogen content of BSG XOS and the conversion factor of 5.83 (AOAC Official Methods of Analysis, 1975; FAO, 2002) was used to express the equivalent amount of protein.

\subsection{Mono- and oligosaccharide composition of the XOS mixtures}

The purified XOS series obtained from EUC, CC and BSG autohydrolysis and commercial XOS (Suntory Ltd., Osaka, Japan) were analysed by HPLC for quantitative carbohydrate analysis. The HPLC system (Waters, Milford, USA) was equipped with an Aminex HPX-87H column (Bio-Rad, Hercules, USA) in combination with a cation $\mathrm{H}^{+}$-guard column (Bio$\mathrm{Rad}$ ) and a refractive index detector (Waters 2410). Elution took place at $50{ }^{\circ} \mathrm{C}$ with $5 \mathrm{mM} \mathrm{H}_{2} \mathrm{SO}_{4}$. OS were quantified by quantitative acid hydrolysis (QAH) of the selected XOS series with $40 \mathrm{~g} / \mathrm{kg}$ of $\mathrm{H}_{2} \mathrm{SO}_{4}$ at $121{ }^{\circ} \mathrm{C}$ for $60 \mathrm{~min}$. OS concentrations were expressed as the increase in sugar monomers after QAH.

\subsection{Intestinal samples}

Intestinal samples were obtained from one healthy 34-dayold Duroc $\times$ Landrace male piglet, fed with a commercial 
weaning diet based on barley and soybean meal. The animal was sacrificed after a $16 \mathrm{~h}$ fasting period for removal of the entire GI tract. Samples from the luminal contents of the terminal ileum, caecum and distal colon were collected into sterile vials. All vials were kept refrigerated until arrival to the laboratory and preparation of the intestinal inocula for the fermentation assays did not exceed $2 \mathrm{~h}$ after collection.

\subsection{Fermentation media}

The nutrient base medium used in the fermentation experiments was modified from Jaskari et al. (1998) and prepared as described previously (Moura, Barata, et al., 2007) except that a $100 \mathrm{mM}$ solution of sodium hydroxide was used as solvent. The medium was deoxygenated with nitrogen and carbon dioxide using a gassing manifold system and $\mathrm{pH}$ was adjusted to 6.8. Nine-milliliter aliquots were distributed into airtight anaerobic culture tubes (Bellco Biotechnology Inc., Vineland, USA), which were capped with butyl rubber stoppers and sealed with aluminium caps (Bellco Biotechnology Inc.) before autoclave sterilisation. Anaerobic stock solutions of Yeast Nitrogen Base (YNB) (Difco, Detroit, Michigan, USA) and XOS were prepared in airtight serum bottles and distributed into the culture tubes, to final concentrations of $5.0 \mathrm{~g} / \mathrm{L}$ of freeze-dried powder.

\subsection{Fermentation experiment}

The inocula for the fermentation experiments were prepared as described by Moura, Barata, et al. (2007). Briefly, the intestinal contents were diluted in reduced physiological saline (RPS), pH 6.8 (Hartemink, 1999) before inoculation. The tubes with the fermentation medium were inoculated with $0.2 \mathrm{~mL}$ of each intestinal dilution, in duplicate (CC XOS) or triplicate (EUC, BSG and commercial XOS) for each combination of inocula/sampling time $(0,11.5,30$ and $72 \mathrm{~h}$ ), and incubated at $37^{\circ} \mathrm{C}$ for $72 \mathrm{~h}$. At each sampling time, cells were harvested by centrifugation and supernatants were filtered for HPLC analysis.

\subsection{DNA isolation and PCR}

NucleoSpin Tissue Kit (Mackerey-Nagel, Düren, Germany) was used to isolate DNA of cells harvested from the fermentation experiments. Total DNA was serially diluted starting from $10 \mathrm{ng}$ (correspondent to $1 / 1$ dil.), to be used as template in PCR reactions. The primers used in this study are presented in Table 1. Amplification reactions with Lactobacillus groupspecific primers were performed according to the optimized protocol previously described for FOS fermentations (Moura, Simões, Gírio, Loureiro-Dias, \& Esteves, 2007). Bifidobacterium genus-specific primers were used according to Matsuki et al. (2002) and Bacteroides/Prevotella specific primers according to Menaia, Simões, Sousa, Moura, and AmaralCollaço (1998). Electrophoresis was performed on 1\% agarose gels in $1 \times$ TAE buffer, and each lane was loaded with a fixed volume of sample. PCR products were visualised using ethidium bromide staining.

\subsection{Quantification of carbohydrates and fermentation products in the fermentation supernatants}

The filtered supernatants from the culture tubes were analysed for carbohydrates and main fermentation products (lactate, acetate, propionate and butyrate) by HPLC with an Aminex HPX-87H column (Bio-Rad, Richmond, USA) against external standards, as described above.

\section{Results \& discussion}

\subsection{Characterisation of the XOS mixtures}

XOS produced by autohydrolysis derived from three different xylan-rich feedstock materials, namely E. globulus wood, corn cobs and brewery's spent grain. The total content in oligo- and monosaccharides of each XOS mixture is presented in Table 2. The composition of each XOS series is primarily determined by the xylan source used in the autohydrolysis treatments. Considering that some feedstocks used for autohydrolysis derived from arabinoxylan-rich materials, the amount of XOS in the mixtures was calculated considering the sum of xylose and arabinose equivalents released by QAH, and xylose-based OS were uniformly referred to as XOS. The glucose released after QAH possibly deriving from glucan of the feedstock materials was referred to as glucose oligomers (GlcOS).

The XOS selected for this study corresponded to mixtures with three different ranges of DP. Commercial XOS comprising mainly xylobiose and xylotriose can be classified as shortchain XOS. The XOS series up to DP 14 from corn cobs (CC XOS) and from brewery's spent grain (BSG XOS) can be referred to as medium-chain XOS. XOS mixtures from

Table 1

Genus- and group-specific primers used in this study

\begin{tabular}{|c|c|c|c|}
\hline Targeted genus or group & Primer designation & Primer sequence $\left(5^{\prime}\right.$ to $\left.3^{\prime}\right)$ & Source or reference \\
\hline Lactobacillus/Pediococcus & $\begin{array}{l}\text { Lab0677F } \\
\text { Lact71R }\end{array}$ & $\begin{array}{l}\text { CTCCATGTGTAGCGGTG } \\
\text { TCAAAACTAAACAAAGTTTC }\end{array}$ & $\begin{array}{l}\text { Heilig et al. (2002) } \\
\text { Moura, Simões, et al. (2007) }\end{array}$ \\
\hline Bifidobacterium & $\begin{array}{l}\text { Bifid-F } \\
\text { Bifid-R }\end{array}$ & $\begin{array}{l}\text { CTCCTGGAAACGGGTGG } \\
\text { GGTGTTCTTCCCGATATCTACA }\end{array}$ & $\begin{array}{l}\text { Matsuki et al. (2002) } \\
\text { Matsuki et al. (2002) }\end{array}$ \\
\hline Bacteroides/Prevotella & $\begin{array}{l}\text { BactrF1 } \\
\text { BactrF2 }\end{array}$ & $\begin{array}{l}\text { GGGGTTCTGAGAGGAAG } \\
\text { ACCCCCCATTGTAACAC }\end{array}$ & $\begin{array}{l}\text { Menaia et al. (1998) } \\
\text { Menaia et al. (1998) }\end{array}$ \\
\hline
\end{tabular}


Table 2

Characterisation of the XOS mixtures used in the fermentations by piglet intestinal inocula. Oligomeric carbohydrates were determined as monomeric equivalents released after QAH

\begin{tabular}{lllll}
\hline & EUC XOS & CC XOS & BSG XOS & Commercial XOS \\
\hline DP range & $2-25$ & $2-14$ & $3-12$ & $2-5$ \\
XOS $^{\mathrm{a}}$ & 807 & 709 & 411 & 833 \\
GlcOS $^{\mathrm{a}}$ & 30 & 57 & 90 & 58 \\
Glucose $^{\mathrm{a}}$ & 7 & $\mathrm{ND}$ & $\mathrm{ND}$ & 10 \\
Xylose $^{\mathrm{a}}$ & 9 & 16 & 11 & 5 \\
Arabinose $^{\mathrm{a}}$ & $\mathrm{ND}$ & 19 & 4 & $\mathrm{ND}$ \\
Others $^{\mathrm{a}}$ & 147 & 199 & 484 & 94 \\
Ara/Xyl $^{\mathrm{b}}$ & 0 & 2 & 20 & 11 \\
AcO/Xyl & 43 & 20 & 12 & 1 \\
UA/Xyl $^{\mathrm{b}}$ & nd & nd & nd & nd \\
\hline ND not & & & &
\end{tabular}

ND, not detected; nd, not determined; EUC XOS, xylo-oligosaccharides produced from E. globulus wood; CC XOS, xylo-oligosaccharides produced from corn cobs; BSG XOS, xylo-oligosaccharides produced from brewery's spent grain; DP, degree of polymerisation; GlcOS, glucose oligomers; Ara, arabinose; Xyl, Xylose; AcO, acetyl substituents; UA, uronic acids.

a/kg dry weight.

b mol/100 mol - molar percentage of released arabinose or acetic acid per released xylose, after QAH.

Eucalyptus wood (EUC XOS) comprising molecules up to DP 25 can be designated as long-chain XOS. The IUB-IUPAC nomenclature defines oligosaccharides as saccharides containing between 2 and 10 sugar moieties (IUB-IUPAC, 1982), although molecules with a molecular range up to 19 monosaccharide units can be considered as NDO (Voragen, 1998). Under a nutritional point of view, oligomeric structures with DP up to 50 can be defined as resistant short-chain carbohydrates (RSCC), which cannot be hydrolysed by mammalian endogenous enzymes of the small intestine (Englyst \& Englyst, 2005). According to this later definition, all XOS mixtures from Table 2 can be classified as RSCC and therefore constitute potential fermentation substrates at the hindgut level.

Because BSG is known by its high protein content (Santos, Jiménez, Bartolomé, Gómez-Cordovés, \& del Nozal, 2003), the nitrogen content of BSG XOS was determined $(48 \mathrm{~g} / \mathrm{kg})$, which corresponds to $278 \mathrm{~g} / \mathrm{kg}$ (dry weight basis) when expressed as protein equivalents. Apparently, the fractionation step included in the present work was not efficient enough to purify BSG XOS (Table 2) and it can be speculated that hydrolysis products from BSG proteins were still included in the selected pool of BSG XOS. Among all the mixtures produced by autohydrolysis, only BSG XOS presented a considerable value for GlcOS (Table 2).

\subsection{Consumption of OS and accumulation of lactate and SCFA in the fermentation media}

The concentrations of XOS, free monosaccharides and SCFA in the fermentation media were monitored for $72 \mathrm{~h}$ (Fig. 1), so as GlcOS concentration of the BSG XOS mixture (Fig. 2). The amount of each OS mixture added to the culture media was standardised on the basis of dry weight of freezedried product $(5 \mathrm{~g} / \mathrm{L})$, which introduced slight differences on mono- and oligosaccharides content in the culture media. The $\mathrm{pH}$ values did not decrease markedly during the $72 \mathrm{~h}$ of the fermentation trials (final $\mathrm{pH} \geq 6.5$ ).

In vitro experiments allow the comparison of rates to which OS are broken down and consumed in fermentation experiments. Therefore, these experiments are important to determine quantifiable parameters suitable for comparing the in vitro fermentability of the different substrates. The decline of XOS concentration in the growth media and the increase in organic acids throughout the fermentations were indicative of extensive microbial fermentation by all the inocula (Fig. 1). No accumulation of monosaccharides occurred as consequence of OS disappearance in the media (Fig. 1). The major differences on XOS consumption profiles occurred on XOS produced by autohydrolysis between the fermentations by the ileal and the large intestine inocula. In the fermentations by the ileal inoculum, the consumption profiles of mediumand long-chain XOS were similar throughout all fermentations. After $30 \mathrm{~h}$, averagely $76 \%$ of the initial amount of these XOS remained in the media as fermentation substrate. Afterwards the concentrations slowly decreased up to $72 \mathrm{~h}$. In the fermentations by the caecal or colonic inocula, medium- and long-chain XOS were all utilised to a similar extent $(<15 \%$ residual) up to $30 \mathrm{~h}$. The highest consumption rates by the caecal or colonic inocula of EUC XOS were determined between 11.5 and $30 \mathrm{~h}$, whereas CC XOS and BSG XOS originated an almost constant consumption rate from 0 up to $30 \mathrm{~h}$. Regarding the contribution of GlcOS of the BSG XOS mixture (Table 2), 84.2, 86.6 and $86.9 \%$ of the initial GlcOS were consumed by the microorganisms from, respectively, the ileal, caecal and colonic inocula up to $11.5 \mathrm{~h}$. In opposition to autohydrolysis XOS, commercial XOS were rapidly consumed by the ileal microbiota, remaining in the medium only $25 \%$ of the initial amount after $30 \mathrm{~h}$. Interestingly, the consumption pattern of commercial XOS by the inocula from the large intestine displayed a trend to resist an initial degradation up to $11.5 \mathrm{~h}$ resembled to that of EUC XOS. The slower fermentation rate of EUC XOS, CC XOS and BSG XOS by the ileal inoculum denotes a lower fermentation efficiency of the foregut microbiota towards longer molecules of XOS, when compared to short-chain XOS. In this study it was not possible to find a correlation between the rate of XOS consumption and their degree of substitution by arabinose or acetyl groups. In order to fulfil the prebiotic criteria (Gibson et al., 2004) XOS need to resist hydrolysis by the microbiota from the upper part of the piglet GI tract. Consequently, the slower fermentability of EUC XOS, CC XOS and BSG XOS by the ileal digesta may indicate their adequacy as more persistent OS, potentially capable of reaching more distal compartments of the porcine GI tract. In a previous study, a series of chemically diverse oligosaccharides including short-chain XOS were compared in their in vitro fermentability by porcine faecal digesta (Smiricky-Tjardes et al., 2003). The slow rate to which short-chain XOS were fermented led the authors to suggest that such XOS would constitute a suitable source of fermentable substrate for the distal portion of the pig GI tract. Our data showed that short-chain XOS were much more 

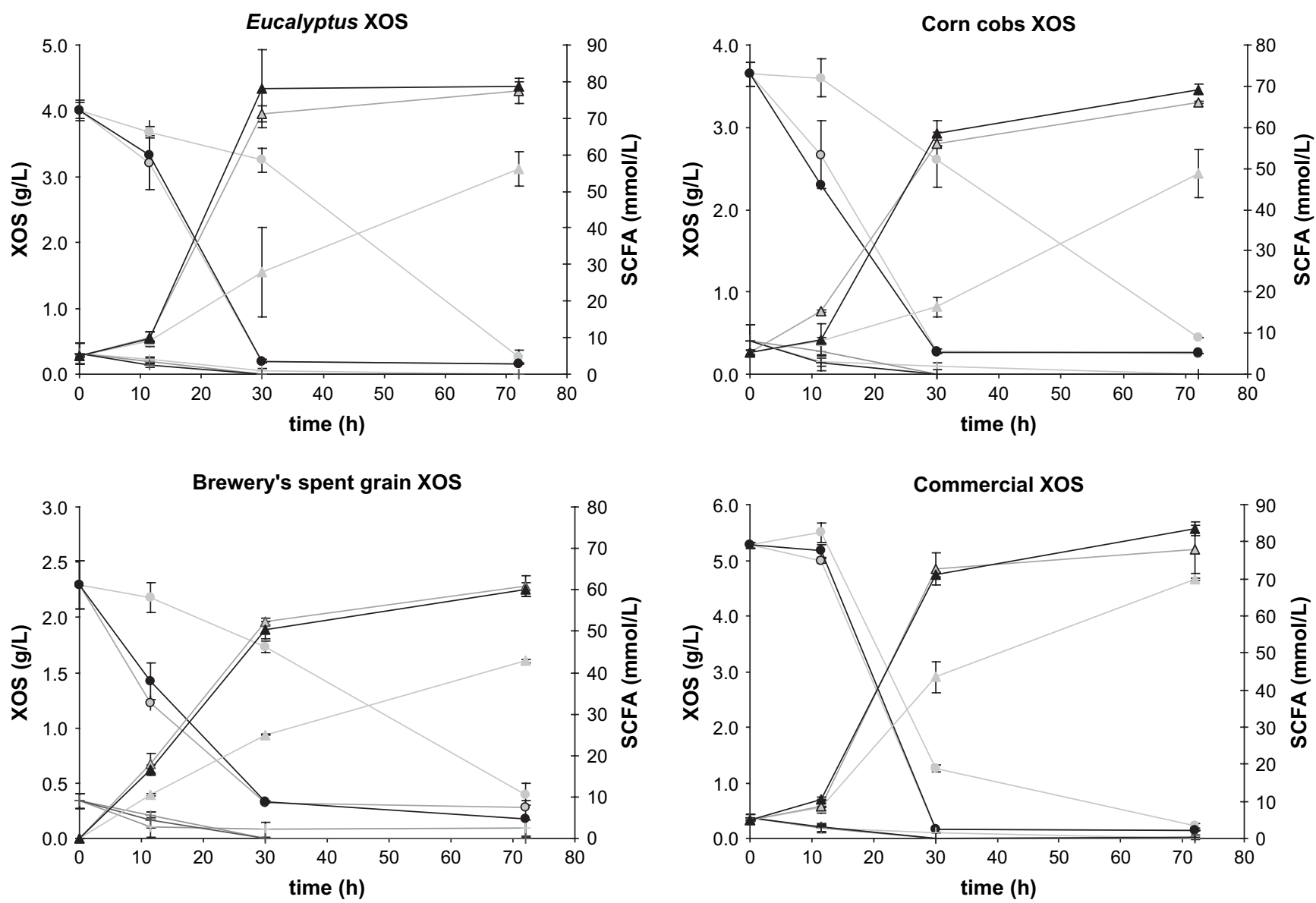

Fig. 1. Consumption of XOS and SCFA accumulation during $72 \mathrm{~h}$ of in vitro fermentation of XOS mixtures from Eucalyptus wood (EUC XOS), corn cobs (CC XOS), brewery's spent grain (BSG XOS) and commercial XOS by the ileal, caecal and colonic inocula. $(O$ XOS, $\triangle$ SCFA, + free monosaccharides; 0 Ileum; O Caecum; C Colon; $\triangle$ Ileum; $\Delta$ Caecum; $\Delta$ Colon; + Ileum; + Caecum; + Colon).

rapidly consumed than EUC XOS, CC XOS or BSG XOS by the ileal digesta. Comparing the consumption profiles, it is possible to advocate an even greater capability of the latter XOS to persist throughout the porcine GI tract.

In vitro methods are also valuable to measure the production of organic acids since these are not absorbed or metabolized as if they were produced in vivo. By using samples from

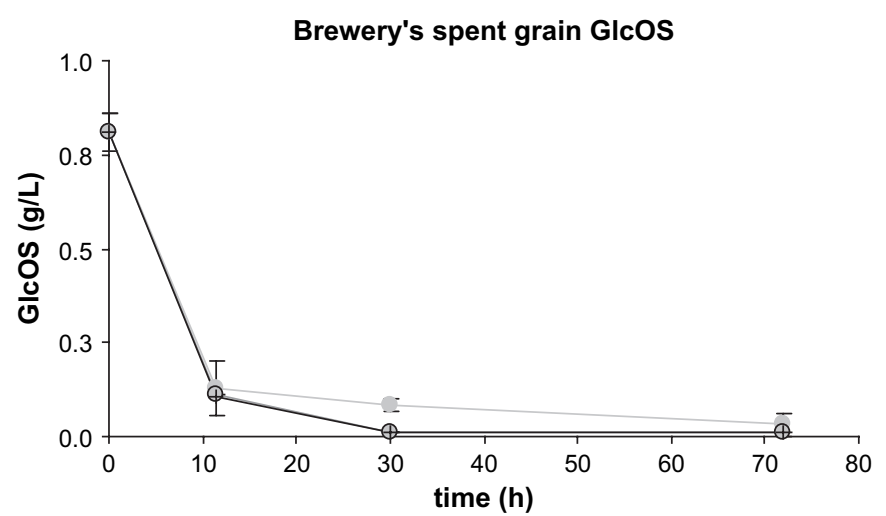

Fig. 2. Consumption of glucose oligomers (GlcOS) during $72 \mathrm{~h}$ of in vitro fermentation of XOS mixtures from brewery's spent grain (BSG XOS) by the ileal, caecal and colonic inocula. ( Ileum; O Caecum; + Colon). piglet digesta collected in different gut compartments, not only the extent of XOS fermentation, but also the type and relative amounts of organic acids produced can be compared. Major SCFA resulting from fermentation in mammalian intestinal tract are acetate, propionate and butyrate, whereas lactate is an intermediate metabolite from the fermentation process (Macfarlane \& Macfarlane, 2003). The amounts of these organic acids accumulated during in vitro fermentation of all the XOS mixtures are represented in Fig. 3. The inocula from the caecum and colon fermented XOS faster (more rapid accumulation of SCFA) and to a greater extent (greatest SCFA accumulation) than the ileal inoculum (Fig. 3). Lactate was typically detected in low concentrations in a first stage of the fermentations. In the fermentations by the ileal inoculum, lactate was detected up to $30 \mathrm{~h}$, although increases from 11.5 to $30 \mathrm{~h}$ were only registered for commercial XOS and CC XOS. Lactate production at the beginning of the experiments is in accordance with the fact that it is an intermediary product of carbohydrate fermentation which can be converted to acetate, propionate and butyrate by common intestinal bacteria (Belenguer et al., 2006; Cotta \& Whitehead, 1998; Duncan, Louis, \& Flint, 2004). Lactate production can be correlated with the involvement of lactic bacteria and bifidobacteria early in the fermentation since they are able to utilise XOS 

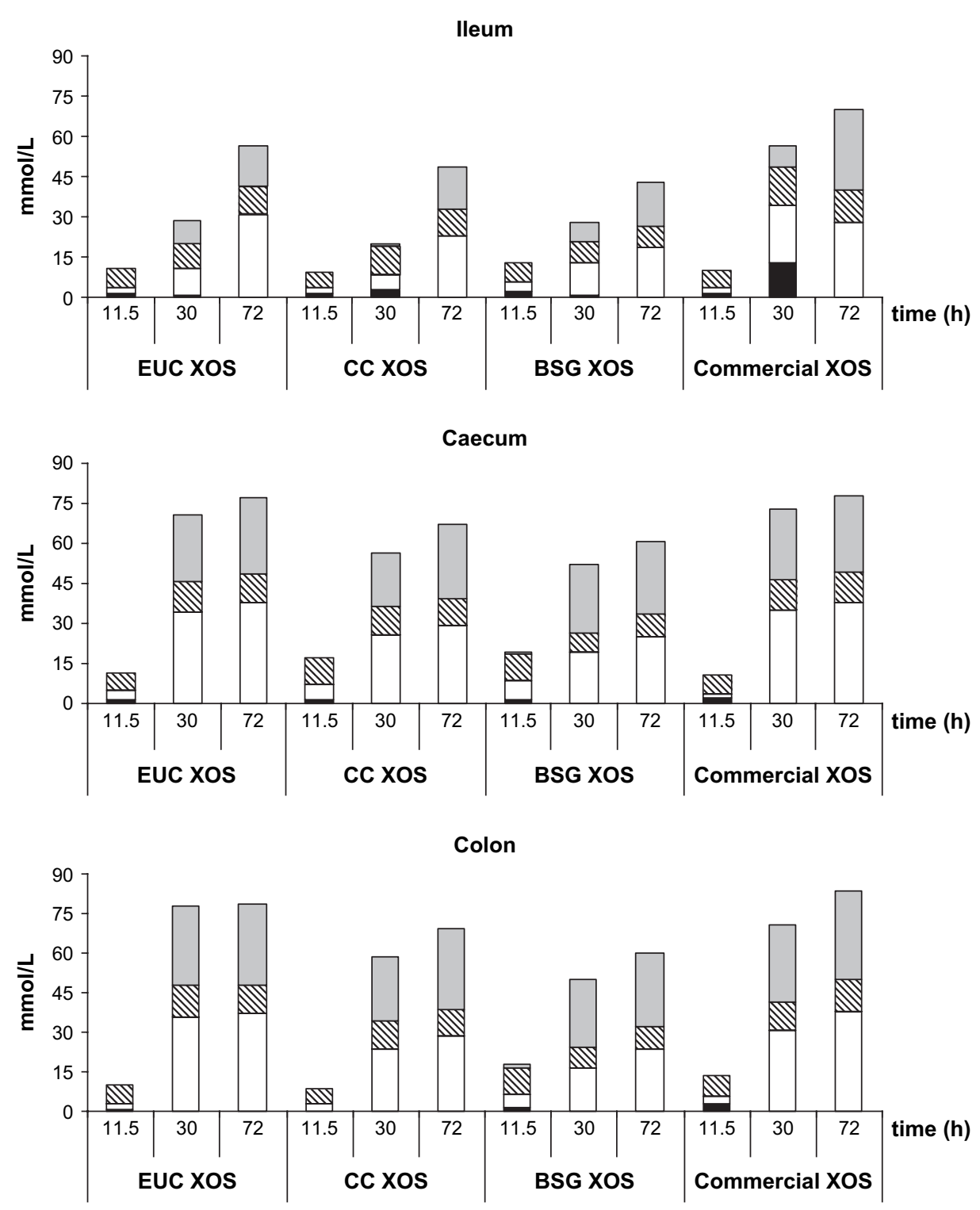

Fig. 3. Accumulation of SCFA and lactate during $72 \mathrm{~h}$ of in vitro fermentation of XOS mixtures from Eucalyptus wood (EUC XOS), corn cobs (CC XOS), brewery's spent grain (BSG XOS) and commercial XOS by the ileal, caecal and colonic inocula. ( $\square$ Lactate, $\square$ Acetate, $\mathbb{\mathbb { N }}$ Propionate, $\square$ Butyrate).

(Crittenden et al., 2002) producing lactate and acetate but not butyrate (Scardovi, 1988). Strains of Selenomonas ruminantium are also described as able to ferment XOS not only to lactate and acetate, but also producing propionate (Cotta \& Whitehead, 1998). Members of this genus were reported to be present in the colonic wall and in the stomach of pigs (Mikkelsen, Højberg, \& Jensen, 2007; Pryde, Richardson, Stewart, \& Flint, 1999). In general, it was observed that propionate concentrations tended to stabilise up to $30 \mathrm{~h}$ or to decrease slightly afterwards. Acetate and butyrate were the major fermentation end-products in all cases; the former was detected in all sampling times, whereas butyrate only started to accumulate after $11.5 \mathrm{~h}$. XOS acetogenic potential observed in this study is in agreement with previous data from in vitro fermentations of commercial XOS using pig faecal contents and in vivo experiments with rats fed with diets supplemented with commercial XOS (Imaizumi, Nakatsu, Sato, Sedarnawati, \&
Sugano, 1991; Smiricky-Tjardes et al., 2003). In the fermentations by the caecal and colonic inocula, the concentrations of both acetate and butyrate increased more rapidly, between 11.5 and $30 \mathrm{~h}$. In the fermentations of EUC XOS and CC XOS by the ileal inoculum, acetate concentrations increased later, from 30 to $72 \mathrm{~h}$, while butyrate concentrations suffered major increases from 30 to $72 \mathrm{~h}$ in all cases.

Exploring the differences between XOS mixtures, the concentrations of acetate and lactate after $30 \mathrm{~h}$ were considerably higher for commercial XOS than for any other XOS mixture in the fermentations by the ileal inoculum, suggesting a correlation with the rapid consumption of short-chain XOS observed from 11.5 to $30 \mathrm{~h}$ (Fig. 1). In a second stage of commercial XOS fermentation by the ileal digesta $(>30 \mathrm{~h})$, in which XOS were $25 \%$ residual in the fermentation media, butyrate accumulated up to a higher concentration as compared to all the other XOS. A better temporal correspondence was observed between 
medium- and long-chain XOS consumption and butyrate production, suggesting the possibility of longer XOS to act as butyrogenic substrates. Butyrate arising from microbial fermentation is important for the energy metabolism and normal development of colonic epithelial cells and presents an important protective role in relation to colonic disease (Pryde, Duncan, Hold, Stewart, \& Flint, 2002). However, the former assumption is in disagreement with results obtained in fermentations of medium-chain XOS by human faecal inocula, where butyrate was mainly produced when all XOS were already degraded (Kabel, Kortenoeven, Schols, \& Voragen, 2002). Some authors refer that the butyrogenic effect of certain dietary substrates can be explained by lactate cross-feeding between genera capable of fermenting oligo- or polysaccharides, which are lactate-producers, and genera capable of utilising lactate, which are butyrate-producers (Belenguer et al., 2006; Duncan et al., 2004). Accordingly, considering that lactate reached a considerable concentration $(13.0 \mathrm{mmol} / \mathrm{L})$ in the fermentation of commercial XOS by the ileal inoculum during the first $30 \mathrm{~h}$, it is expected that substantial lactate fermentation to butyrate has occurred. Since a rapid fermentation rate of lactate to butyrate and/or acetate may turn lactate undetectable, it is not possible to rule out the same hypothesis for the other fermentations of this study. Similar observations have already been registered in controlled co-cultures of lactate-producers and lactate-utilisers/butyrate-producers using starch as carbohydrate energy source (Duncan et al., 2004).

Considering the contribution of GlcOS in the mixture from BSG autohydrolysis and the fact that it was considerably consumed up to $11.5 \mathrm{~h}$ (Fig. 2), some differences could be expected in the fermentation products accumulated in the media during the same time period. In the fermentations by the colonic digesta, acetate and propionate concentrations were slightly higher at $11.5 \mathrm{~h}$ as compared to other XOS and very small amounts of butyrate were already detected up to $11.5 \mathrm{~h}$ in the fermentations by the caecal and colonic inocula.

\subsection{PCR titres}

The Lactobacillus/Pediococcus and Bacteroides/Prevotella group-specific and Bifidobacterium genus-specific primer pairs listed in Table 1 were used to determine the maximum dilution of total DNA able to produce PCR amplification (PCR titre). The PCR titres determined throughout XOS fermentations by the ileal, caecal and colonic inocula are presented in Fig. 4. Considering that the PCR titre corresponds to a detection limit (Wang, Cao, \& Cerniglia, 1996) which depends on the proportion of targeted DNA among total DNA, it should allow to monitor shifts of targeted bacterial groups in mixed culture fermentations. The aim of determining PCR titres was to compare the efficacy of the different XOS mixtures to support the replication of bifidobacteria and lactobacilli, more specifically to evaluate XOS potential to act as selective substrate and/or to affect the targeted bacterial groups differently depending on the GI section from which each inocula was collected.

The PCR titres obtained with Lab0677F + Lact71R attained considerable values at the beginning of the fermentations.
Except for BSG XOS, increases of the PCR titres with Lab0677F + Lact71R were only noticed from 0 up to $11.5 \mathrm{~h}$ for all the inocula. In the fermentations by the ileal inoculum, commercial XOS supported the major increase with the former primer pair. After $11.5 \mathrm{~h}$, the PCR titres produced with Lab0677F + Lact71R and the ileal inoculum in the fermentations of commercial XOS decreased steadily up to $72 \mathrm{~h}$. This decrease was less pronounced for CC XOS and the value of the PCR titre of EUC XOS at $30 \mathrm{~h}$ was maintained up to $72 \mathrm{~h}$. In the fermentations by the caecal inoculum, increases in the PCR titres produced with Lab0677F + Lact71R were more pronounced for commercial XOS and EUC XOS. BSG XOS gave rise to the Lactobacillus/Pediococcus profile presenting the lowest increase from 0 up to $11.5 \mathrm{~h}$ in the fermentations by caecal inoculum. The maximal PCR titres from Lactobacillus/Pediococcus detection were attained up to $11.5 \mathrm{~h}$ in the fermentations of commercial XOS by the inoculum from the colon. Bifidobacteria were not detected in any sample at $0 \mathrm{~h}$. However, increases in the PCR titres determined at $11.5 \mathrm{~h}$ in the fermentations of EUC XOS, CC XOS and commercial XOS by the ileal inoculum denoted that bifidobacterial replication was stimulated in a first stage of fermentation. BSG XOS were unable to raise notably bifidobacterial PCR titres in the fermentations by the ileal inoculum. In the fermentations by the caecal inoculum, the PCR titre profiles obtained with Bifid-F + Bifid-R showed an increase up to $11.5 \mathrm{~h}$ on EUC XOS and BSG XOS, and up to $30 \mathrm{~h}$ on CC XOS. Surprisingly, commercial XOS were unable to produce a notable increase on bifidobacterial detection limit in the fermentations by microorganisms from the caecum. The most consistent increases on Bifidobacterium PCR titres in the fermentations by the colonic inoculum were obtained for commercial XOS and CC XOS. In these cases, PCR titres increased from 0 to $11.5 \mathrm{~h}$, more notably for commercial XOS than for CC XOS, and the values were maintained up to $30 \mathrm{~h}$ for CC XOS and up to $72 \mathrm{~h}$ for commercial XOS. According to the results of the PCR titres (Fig. 4), the replication of Bifidobacterium and Lactobacillus/Pediococcus was enhanced at the beginning of the fermentations, in most cases up to $11.5 \mathrm{~h}$. Lactic acid bacteria are common inhabitants of the porcine GI tract (Jensen, 2001). Lactobacillus/Enterococcus constitute a stable population along the porcine intestinal tract (Franklin, Mathew, Vickers, \& Clift, 2002; Mountzouris et al., 2006) which is in agreement with the PCR titres obtained with Lab0677F + Lact71R at the beginning of the fermentations. Irrespective of the inocula, the XOS with the highest impact (highest increase on the detection limit) on Lactobacillus/Pediococcus replication were commercial XOS. Particularly in the fermentations of commercial XOS by the ileal inoculum, increases on Lab0677F + Lact71R PCR titres were concomitant with the highest lactate concentrations up to $30 \mathrm{~h}$ (Fig. 3) which agrees with the proportional relevance of lactobacilli in the proximal intestinal regions of the porcine GI tract (Jensen, 2001). In opposition to lactic acid bacteria, bifidobacteria represent a minor proportion of the intestinal microbiota in the porcine GI tract (Mikkelsen, Bendixen, Jakobsen, \& Jensen, 2003), which is in accordance with no amplification produced by PCR with the 

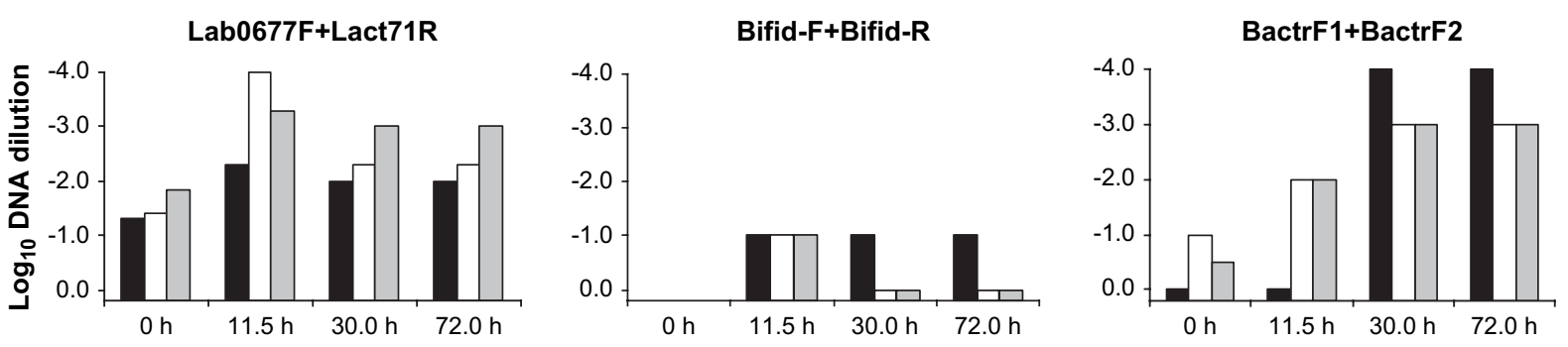

EUC XOS
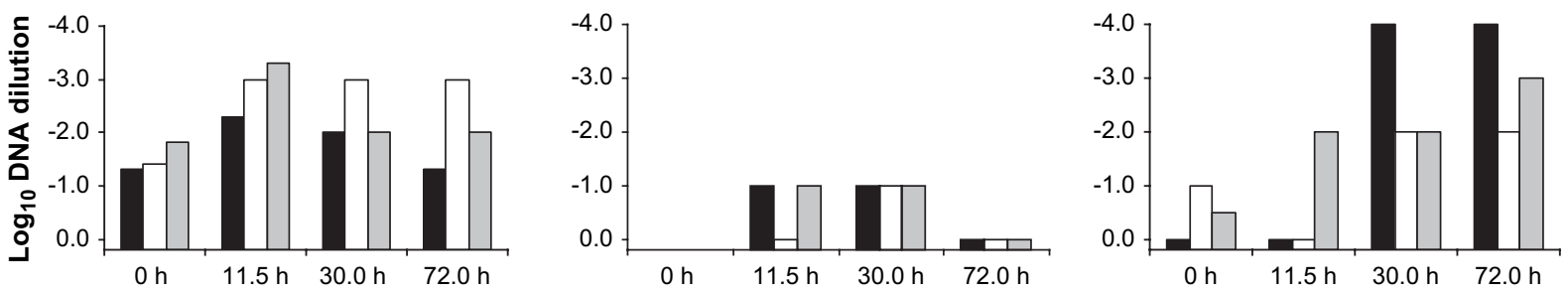

cc xos
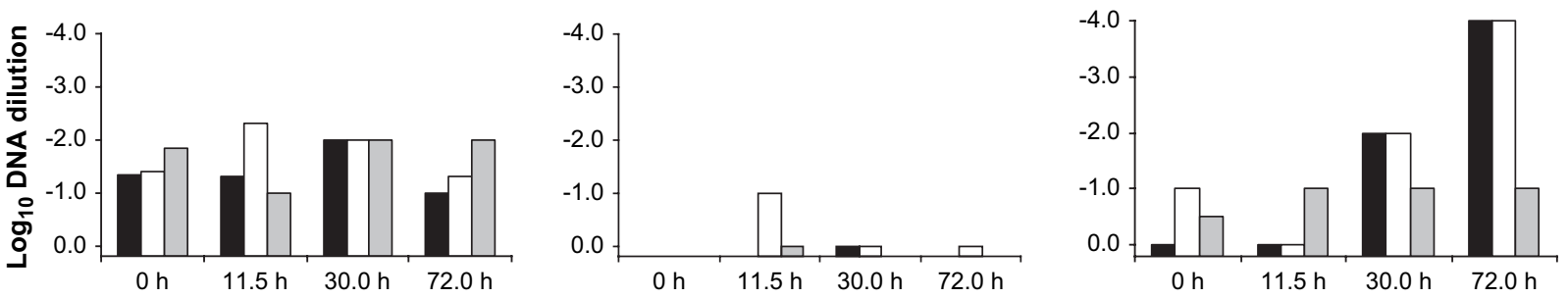

BSG XOS
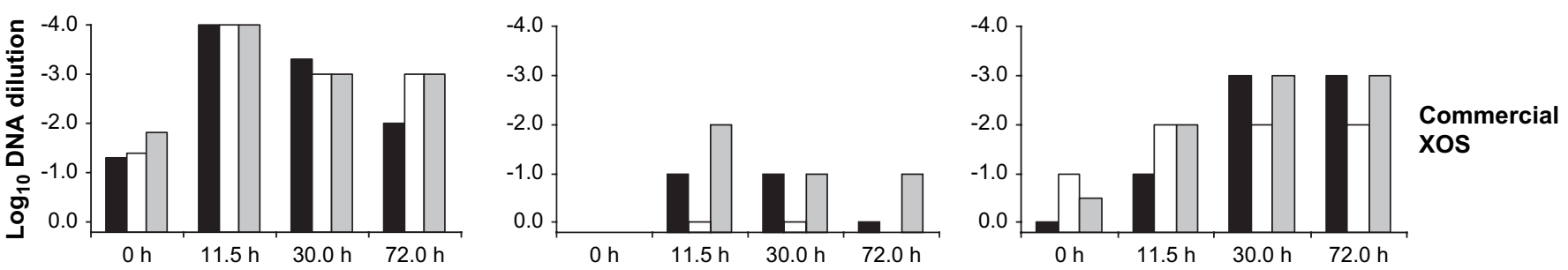

Fig. 4. $\log _{10}$ values of the maximal dilutions of total DNA (isolated at $0,11.5,30$ and $72 \mathrm{~h}$ from XOS fermentations by the ileal, caecal and colonic inocula) capable of producing the expected amplicon by PCR using the primer pairs Lab0677F + Lact71R, Bifid-F + Bifid-R or BactrF1 + BactrF2. Values were based in duplicates of independent positive PCR reactions, and values for $0 \mathrm{~h}$ were averaged for the respective inoculum and primer pair. ( $\square$ Ileum, $\square$ Caecum, $\square$ Colon)

primer pair Bif-F + Bif- $\mathrm{R}$ in the samples from $0 \mathrm{~h}$. The subsequent increases on the PCR titres obtained with this primer pair indicate that bifidobacteria were able to replicate up to detectable levels in the first stage of most XOS fermentations. Commercial XOS demonstrated the highest efficacy (highest increase on the detection limit and subsequent maintenance of a detectable level of bifidobacteria) in stimulating bifidobacterial replication in the fermentation by the colonic inoculum, immediately followed by CC XOS. The preference of bifidobacteria to utilise short-chain XOS in vitro has already been described (Crittenden et al., 2002). In vivo, the bifidogenic character of short-chain XOS has been reported in humans and rats (Campbell, Fahey, \& Wolf, 1997; Hsu, Liao, Chung, Hsieh, \& Chan, 2004; Okazaki et al., 1990). This bifidogenic potential of XOS is a promising characteristic in pig nutrition since it is general consensus that the effect is inversely related to the initial bifidobacterial counts of human volunteers or animals (Morishita et al., 1993; Van Loo et al., 1999). In spite of the diverse DP, EUC XOS, CC XOS and commercial XOS originated similar profiles of enhancement of bifidobacterial replication in the fermentations by the ileal inoculum (Fig. 4), and EUC XOS was able to maintain the bifidobacterial detection level further up to $72 \mathrm{~h}$ denoting some temporal coincidence with the respective consumption profile (Fig. 1). The maintenance of Bifidobacterium PCR titres at considerable detection levels up to $72 \mathrm{~h}$ in the case of EUC XOS (ileal digesta) and commercial XOS (colonic digesta) suggests that this bacterial group was able to attain a considerable representation throughout the fermentations, which is a desirable characteristic regarding XOS prebiotic potential.

The replication of Bacteroides/Prevotella occurred typically in a second stage of fermentation. In the fermentations by the ileal inoculum, PCR titres were inexpressive at $0 \mathrm{~h}$ but the values increased markedly from 11.5 to $30 \mathrm{~h}$ in all cases. The values were maintained or increased up to $72 \mathrm{~h}$ and were higher for XOS produced by autohydrolysis than for commercial XOS. With the caecal inoculum, Bacteroides/Prevotella PCR titres increased progressively up to $30 \mathrm{~h}$ in the fermentations of EUC XOS. Comparatively, this increase occurred only up to $11.5 \mathrm{~h}$ on commercial XOS. 
CC XOS reached the highest BactrF1 + BactrF2 PCR titre at $30 \mathrm{~h}$, whereas BSG XOS maximum was detected at $72 \mathrm{~h}$. In the fermentations of commercial XOS and EUC XOS by the colonic inoculum the detection level of Bacteroides/Prevotella increased steadily up to $30 \mathrm{~h}$ and maintained the value up to $72 \mathrm{~h}$. CC XOS produced a similar detection pattern except that the maximum PCR titre was only attained in the samples from $72 \mathrm{~h}$. BSG XOS seemed unable to enhance replication of Bacteroides/Prevotella in the fermentations by colonic microorganisms. In order to compose some hypothesis concerning XOS capability to selectively stimulate the replication of beneficial bacteria it would be of utmost importance the establishment of a clear correlation between PCR up-shifts observed for Bifidobacterium and Lactobacillus/Pediococcus populations and XOS consumption profiles. Except in the fermentation of CC XOS by the colonic digesta, this correlation was not possible to set since the replication of these bacterial groups was mainly enhanced during the first $11.5 \mathrm{~h}$. In fact, it was easier to identify a temporal coincidence between the highest XOS consumption rates and increases in PCR titres of Bacteroides/Prevotella populations than of bifidobacteria or lactobacilli, even for the ileal inoculum. Bacteroides strains are described as able to utilise commercial XOS (Crittenden et al., 2002). Consequently, the suggestion that medium- and long-chain XOS are not selective for bifidobacterial and/or lactobacilli growth would be consensual with previous observations for short-chain XOS. Considering that Bacteroides/ Prevotella replication occurs mainly in a second stage of fermentation, it is not possible from this study to evaluate whether growth can be a direct result of XOS hydrolysis and uptake or of cross-feeding of intermediate substrates resulting from OS breakdown (Belenguer et al., 2006) or even from intermediate fermentation of lactate, as discussed above. More complete studies involving carbon flow analysis in controlled co-cultures would be necessary to enlighten these issues.

\section{Conclusions}

From this study, it can be concluded that XOS produced by autohydrolysis with a DP range up to 25 can be fermented in vitro by the ileal, caecal and colonic microbiota of a Duroc $\times$ Landrace piglet. The longer chain length of the XOS mixtures produced by autohydrolysis reduced notably the rate of XOS consumption in the fermentations by the microbiota from the piglet's ileum. EUC XOS, CC XOS and commercial XOS supported an enhancement of bifidobacteria and lactobacilli replication in a first stage of fermentation, up to $11.5 \mathrm{~h}$. Apparently this stimulation was not selective, because Bacteroides/Prevotella replication increased in a second stage of fermentation, coincident in time with the highest consumption rates of some XOS mixtures tested. Mostly due to the slow fermentability by the ileal inocula, EUC XOS, CC XOS and BSG XOS can be regarded as promising functional candidates suitable to act as distally fermentable substrates. Amongst the mixtures produced by autohydrolysis, EUC XOS and CC XOS appeared to be more promising than BSG XOS in stimulating bifidobacteria and lactobacilli replication in vitro.

\section{Acknowledgments}

The authors are grateful to the Commission of the European Community and the FEDER Funds for financial support of this work (Project POCTI/CVT/37545/2002) and to the EU Project FAIR CT98-3811. The authors would like to thank J.P.B. Freire from Departamento de Produção Agrícola e Animal, Instituto Superior de Agronomia, Lisboa, for providing the piglet intestinal samples and for the fruitful discussions concerning the analysis of the fermentation data.

\section{References}

AOAC. (1975). AOAC Official Methods of Analysis. Washington, DC: AOAC. Belenguer, A., Duncan, S. H., Calder, A. G., Holtrop, G., Louis, P., \& Lobley, G. E., et al. (2006). Two routes of metabolic cross-feeding between Bifidobacterium adolescentis and butyrate-producing anaerobes from the human gut. Applied and Environmental Microbiology, 72, 3593-3599.

Campbell, J. M., Fahey, G. C., \& Wolf, B. W. (1997). Selected indigestible oligosaccharides affect large bowel mass, cecal and fecal short-chain fatty acids, $\mathrm{pH}$ and microflora in rats. Journal of Nutrition, 127, 130-136.

Carvalheiro, F., Esteves, M. P., Parajó, J. C., Pereira, H., \& Gírio, F. M. (2004). Production of oligosaccharides by autohydrolysis of brewery's spent grain. Bioresource Technology, 91, 93-100.

Carvalheiro, F., Garrote, G., Parajó, J. C., Pereira, H., \& Gírio, F. M. (2005) Kinetic modeling of brewery's spent grain autohydrolysis. Biotechnology Progress, 21, 233-243.

Cotta, M. A., \& Whitehead, T. R. (1998). Xylooligosaccharide utilization by the ruminal anaerobic bacterium Selenomonas ruminantium. Current Microbiology, 36, 183-189.

Crittenden, R. G., Karppinen, S., Ojanen, S., Tenkanen, M., Fagerström, R., \& Mättö, J., et al. (2002). In vitro fermentation of cereal dietary fibre carbohydrates by probiotic and intestinal bacteria. Journal of the Science of Food and Agriculture, 82, 781-789.

Duncan, S. H., Louis, P., \& Flint, H. J. (2004). Lactate-utilizing bacteria, isolated from human feces, that produce butyrate as a major fermentation product. Applied and Environmental Microbiology, 70, 5810-5817.

Ebringerová, A., Hromádková, Z., \& Heinze, T. (2005). Hemicellulose. Polysaccharides 1: Structure, characterization and use, 186, 1-67.

Englyst, K. N., \& Englyst, H. N. (2005). Carbohydrate bioavailability. British Journal of Nutrition, 94, 1-11.

FAO. (2002). Food and Nutrition, Paper 77, Food energy - methods of analysis and conversion factors.

Franklin, M. A., Mathew, A. G., Vickers, J. R., \& Clift, R. A. (2002). Characterization of microbial populations and volatile fatty acid concentrations in the jejunum, ileum, and cecum of pigs weaned at 17 vs 24 days of age. Journal of Animal Science, 80, 2904-2910.

Garrote, G., Domínguez, H., \& Parajó, J. C. (1999a). Hydrothermal processing of lignocellulosic materials. Holz Als Roh-und Werkstoff, 57, 191-202.

Garrote, G., Domínguez, H., \& Parajó, J. C. (1999b). Mild autohydrolysis: an environmentally friendly technology for xylooligosaccharide production from wood. Journal of Chemical Technology and Biotechnology, 74, 1101-1109.

Gibson, G. R., McCartney, A. L., \& Rastall, R. A. (2005). Prebiotics and resistance to gastrointestinal infections. British Journal of Nutrition, 93, S31-S34.

Gibson, G. R., Probert, H. M., Van Loo, J., Rastall, R. A., \& Roberfroid, M. B. (2004). Dietary modulation of the human colonic microbiota: updating the concept of prebiotics. Nutrition Research Reviews, 17, 259-275.

Hartemink, R. (1999). Prebiotic effects of non-digestible oligo- and polysaccharides. PhD thesis, Agrotechnology \& Food Sciences Group, Wageningen Agricultural University, the Netherlands.

Heilig, H. G. H. J., Zoetendal, E. G., Vaughan, E. E., Marteau, P., Akkermans, A. D. L., \& de Vos, W. M. (2002). Molecular diversity of Lactobacillus spp. and other lactic acid bacteria in the human intestine as determined by specific amplification of $16 \mathrm{~S}$ ribosomal DNA. Applied and Environmental Microbiology, 68, 114-123. 
Hsu, C. K., Liao, J. W., Chung, Y. C., Hsieh, C. P., \& Chan, Y. C. (2004). Xylooligosaccharides and fructooligosaccharides affect the intestinal microbiota and precancerous colonic lesion development in rats. Journal of Nutrition, 134, 1523-1528.

Imaizumi, K., Nakatsu, Y., Sato, M., Sedarnawati, Y., \& Sugano, M. (1991). Effects of xylooligosaccharides on blood-glucose, serum and liver lipids and cecum short-chain fatty-acids in diabetic rats. Agricultural and Biological Chemistry, 55, 199-205.

IUB-IUPAC. (1982). Abbreviated terminology of oligosaccharide chains. The Journal of Biological Chemistry, 257, 3347-3351.

Jaskari, J., Kontula, P., Siitonen, A., Jousimies-Somer, H., MattilaSandholm, T., \& Poutanen, K. (1998). Oat beta-glucan and xylan hydrolysates as selective substrates for Bifidobacterium and Lactobacillus strains. Applied Microbiology and Biotechnology, 49, 175-181.

Jensen, B. B. (2001). In A. Piva, K. E. B. Knudsen, \& J. E. Lindberg (Eds.), Gut environment of pigs (pp. 181-200). Nottingham, UK: Nottingham University Press.

Kabel, M. A., Kortenoeven, L., Schols, H. A., \& Voragen, A. G. J. (2002). In vitro fermentability of differently substituted xylo-oligosaccharides. Journal of Agricultural and Food Chemistry, 50, 6205-6210.

Kabel, M. A., Schols, H. A., \& Voragen, A. G. J. (2002). Complex xylooligosaccharides identified from hydrothermally treated Eucalyptus wood and brewery's spent grain. Carbohydrate Polymers, 50, 191-200.

Macfarlane, S., \& Macfarlane, G. T. (2003). Regulation of short-chain fatty acid production. Proceedings of the Nutrition Society, 62, 67-72.

Matsuki, T., Watanabe, K., Fujimoto, J., Miyamoto, Y., Takada, T., \& Matsumoto, K., et al. (2002). Development of 16S rRNA-gene-targeted group-specific primers for the detection and identification of predominant bacteria in human feces. Applied and Environmental Microbiology, 68, $5445-5451$

Menaia, J. A. G. F., Simões, F., Sousa, A. T., Moura, P., \& Amaral-Collaço, M. T. (1998). Bacteroides spp. as alternative indicator organisms: monitoring through PCR 16S-rRNA amplification. Proceedings of the OECD Workshop Interlaken 98 on Molecular Technologies for Safe Drinking Water, Interlaken, Switzerland.

Mikkelsen, L. L., Bendixen, C., Jakobsen, M., \& Jensen, B. B. (2003). Enumeration of bifidobacteria in gastrointestinal samples from piglets. Applied and Environmental Microbiology, 69, 654-658.

Mikkelsen, L. L., Højberg, O., \& Jensen, B. B. (2007). Coarse structured feed stimulates members of the genera Lactobacillus and Mitsuokella as well as propionate and butyrate producers in the pig stomach. Livestock Science, 109, 153-156.

Morishita, Y., Yamada, H., Shiiba, K., Kimura, N., \& Taniguchi, H. (1993). Effect of hydrolyzate of wheat bran hemicellulose on the cecal microflora and short-chain fatty acid concentrations in rats and mice. Bifidobacteria Microflora, 12, 19-24.

Mountzouris, K. C., Balaskas, C., Fava, F., Tuohy, K. M., Gibson, G. R., \& Fegeros, K. (2006). Profiling of composition and metabolic activities of the colonic microflora of growing pigs fed diets supplemented with prebiotic oligosaccharides. Anaerobe, 12, 178-185.

Moura, P., Barata, R., Carvalheiro, F., Gírio, F., Loureiro-Dias, M. C., \& Esteves, M. P. (2007). In vitro fermentation of xylo-oligosaccharides from corn cobs autohydrolysis by Bifidobacterium and Lactobacillus strains. LWT - Food Science and Technology, 40, 963-972.

Moura, P., Simões, F., Gírio, F., Loureiro-Dias, M. C., \& Esteves, M. P. (2007). PCR monitoring of Lactobacillus and Bifidobacterium dynamics in fermentations by piglet intestinal microbiota. Journal of Basic Microbiology, 47, 148-157.

Okazaki, M., Fujikawa, S., \& Matsumoto, N. (1990). Effect of xylooligosaccharide on the growth of bifidobacteria. Bifidobacteria Microflora, 9, $77-86$.

Palframan, R., Gibson, G. R., \& Rastall, R. (2003). Carbohydrate preferences of Bifidobacterium species isolated from the human gut. Current Issues in Intestinal Microbiology, 4, 71-75.

Patterson, J. A. (2005). Prebiotic feed additives: rationale and use in piglets. Advances in Pork Production, 16, 149-159.

Pool-Zobel, B. L. (2005). Inulin-type fructans and reduction in colon cancer risk: review of experimental and human data. British Journal of Nutrition, 93, S73-S90.

Pryde, S. E., Duncan, S. H., Hold, G. L., Stewart, C. S., \& Flint, H. J. (2002). The microbiology of butyrate formation in the human colon. Fems Microbiology Letters, 217, 133-139.

Pryde, S. E., Richardson, A. J., Stewart, C. S., \& Flint, H. J. (1999). Molecular analysis of the microbial diversity present in the colonic wall, colonic lumen, and cecal lumen of a pig. Applied and Environmental Microbiology, 65, 5372-5377.

Rastall, R. A., \& Maitin, V. (2002). Prebiotics and synbiotics: towards the next generation. Current Opinion in Biotechnology, 13, 490-496.

Santos, M., Jiménez, J. J., Bartolomé, B., Gómez-Cordovés, C., \& del Nozal, M. J. (2003). Variability of brewer's spent grain within a brewery. Food Chemistry, 80, 17-21.

Scardovi, V. (1988). In P. H. A. Sneath, N. S. Mair, M. E. Sharpe, \& J. G. Holt (Eds.), Bergey's manual of systematic bacteriology, Vol. 2 (pp. 14181434). London, UK: Williams \& Wilkins.

Smiricky-Tjardes, M. R., Flickinger, E. A., Grieshop, C. M., Bauer, L. L., Murphy, M. R., \& Fahey, G. C. (2003). In vitro fermentation characteristics of selected oligosaccharides by swine fecal microflora. Journal of Animal Science, 81, 2505-2514.

Tuohy, K. M., Rouzaud, G. C. M., Bruck, W. M., \& Gibson, G. R. (2005). Modulation of the human gut microflora towards improved health using prebiotics - assessment of efficacy. Current Pharmaceutical Design, 11, 75-90.

van de Wiele, T., Boon, N., Possemiers, S., Jacobs, H., \& Verstraete, W. (2007). Inulin-type fructans of longer degree of polymerisation exert more pronounced in vitro prebiotic effects. Journal of Applied Microbiology, 102, 452-460.

Van Laere, K. M. J., Hartemink, R., Bosveld, M., Schols, H. A., \& Voragen, A. G. J. (2000). Fermentation of plant cell wall derived polysaccharides and their corresponding oligosaccharides by intestinal bacteria. Journal of Agricultural and Food Chemistry, 48, 1644-1652.

Van Loo, J., Cummings, J., Delzenne, N., Englyst, H., Franck, A., \& Hopkins, M., et al. (1999). Functional food properties of nondigestible oligosaccharides: a consensus report from the ENDO project (DGXII AIRII-CT94-1095). British Journal of Nutrition, 81, 121-132.

Voragen, A. G. J. (1998). Technological aspects of functional food-related carbohydrates. Trends in Food Science \& Technology, 9, 328-335.

Wang, R. F., Cao, W. W., \& Cerniglia, C. E. (1996). PCR detection and quantitation of predominant anaerobic bacteria in human and animal fecal samples. Applied and Environmental Microbiology, 62, 1242-1247.

Watzl, B., Girrbach, S., \& Roller, M. (2006). Inulin, oligofructose and immunomodulation. British Journal of Nutrition, 93, S49-S55. 